\title{
Donor-Derived Genotype 4 Hepatitis E Virus Infection, Hong Kong, China, 2018
}

\author{
Siddharth Sridhar, Vincent C.C. Cheng, Shuk-Ching Wong, Cyril C.Y. Yip, \\ Shusheng Wu, Anthony W.I. Lo, Kit-Hang Leung, Winger W.N. Mak, Jianpiao Cai, \\ Xin Li, Jasper F.W. Chan, Susanna K.P. Lau, Patrick C.Y. Woo, Wai-Ming Lai, \\ Tze-Hoi Kwan, Timmy W.K. Au, Chung-Mau Lo, Sally C.Y. Wong, Kwok-Yung Yuen
}

\begin{abstract}
Hepatitis E virus (HEV) genotype 4 (HEV-4) is an emerging cause of acute hepatitis in China. Less is known about the clinical characteristics and natural history of HEV-4 than HEV genotype 3 infections in immunocompromised patients. We report transmission of HEV-4 from a deceased organ donor to 5 transplant recipients. The donor had been viremic but HEV IgM and IgG seronegative, and liver function test results were within reference ranges. After a mean of 52 days after transplantation, hepatitis developed in all 5 recipients; in the liver graft recipient, disease was severe and with progressive portal hypertension. Despite reduced immunosuppression, all HEV-4 infections progressed to persistent hepatitis. Four patients received ribavirin and showed evidence of response after 2 months. This study highlights the role of organ donation in HEV transmission, provides additional data on the natural history of HEV-4 infection, and points out differences between genotype 3 and 4 infections in immunocompromised patients.
\end{abstract}

$\mathrm{H}$ epatitis E virus (HEV; genus Orthohepevirus) is a major cause of hepatitis globally (1). In immunocompetent persons, it typically causes self-limited acute hepatitis. In immunocompromised persons, such as transplant recipients, HEV infection can persist, causing chronic hepatitis and cirrhosis (2). HEV-A, the main HEV virus of relevance to human health, is classified into 8 genotypes, of which 5 can infect humans (3). Persistent hepatitis E is most commonly reported for patients infected with HEV genotype 3 (HEV-3), the prevalent genotype infecting humans in Europe and the Americas (4-8). In many parts of

Author affiliations: The University of Hong Kong, Hong Kong, China (S. Sridhar, V.C.C. Cheng, S.-C. Wong, C.C.Y. Yip, S. Wu, K.-H. Leung, W.W.N. Mak, J. Cai, X. Li, J.F.W. Chan, S.K.P. Lau, P.C.Y. Woo, C.-M. Lo, S.C.Y. Wong, K.-Y. Yuen); Queen Mary Hospital, Hong Kong (A.W.I. Lo, T.W.K. Au); Princess Margaret Hospital, Hong Kong (W.-M. Lai); Tuen Mun Hospital, Hong Kong (T.-H. Kwan)

DOI: https://doi.org/10.3201/eid2503.181563
China, HEV genotype 4 (HEV-4) has rapidly emerged as the most common genotype causing acute hepatitis $(9,10)$. We recently demonstrated that, similar to HEV-3, HEV4 can cause persistent infections in transplant recipients (11). However, data on the natural history and ribavirin responsiveness of HEV-4 infections in immunocompromised patients are limited.

HEV-3 and HEV-4 are predominantly transmitted by food, specifically undercooked pork products. Transmission through blood product transfusion has also been well documented $(12,13)$, prompting many countries to consider screening blood products for HEV (14). Less frequently reported is HEV transmission via transplanted organs $(15,16)$.

In August 2018, chronic HEV-4 infection developed in 2 transplant recipients who had received organs from a common donor. In response, we conducted an investigation to 1) identify other infected recipients from the same donor, 2) confirm that the infection was indeed donor derived, 3 ) investigate the natural history of HEV-4 infection, and 4) study outcomes of infected patients who received ribavirin.

\section{Materials and Methods}

\section{Study Setting, Patients, and Samples}

In Hong Kong, Queen Mary Hospital is the liver and heartlung transplantation center, Princess Margaret Hospital is a kidney transplant center, and Tuen Mun Hospital offers specialist follow-up services for kidney transplant recipients. HEV diagnostic testing for this study was performed at the University of Hong Kong Department of Microbiology, based at Queen Mary Hospital. We retrieved patient identifiers for the organ donor and recipients from the organ donor registry and retrieved clinical details for donor and recipients from the electronic patient record. Archived serum samples from the donor and all recipients were retrieved and subjected to HEV quantitative real-time reverse transcription PCR (qRT-PCR) and serologic testing. Ethics 
approval for this study was obtained from the institutional review board of the University of Hong Kong/Hospital Authority Hong Kong West Cluster.

\section{HEV Diagnostic Testing, Sequencing, and Phylogenetic Analysis}

For serologic testing, we used HEV IgM and HEV IgG ELISA kits (Wantai, http://www.ystwt.cn/HEV.html). In addition, we tested donor and recipient serum samples by using $\operatorname{IgG}$ and $\operatorname{IgM}$ Western blots as previously described (17). HEV qRT-PCR was performed as previously described (18). Protocols for the Western blot, HEV qRT-PCR, sequencing, and phylogenetic analysis are described in the Appendix (https://wwwnc.cdc.gov/EID/ article/25/3/18-1563-App1.pdf).

\section{Liver Histology and Immunohistochemistry}

Liver tissue sections from the organ donor and liver graft recipient were available for histologic analysis with hematoxylin and eosin staining. We performed immunohistochemical staining with monoclonal antibody against HEV open reading frame 2 (kindly provided by N.S. Xia, Xiamen University, Xiamen, China) on tissue sections, as previously described (19).

\section{Case Definitions}

Patients were defined as having hepatitis E if HEV qRTPCR detected HEV RNA in their plasma. Patients were defined as having probable donor-derived hepatitis $\mathrm{E}$ if they had received organ transplant from the viremic donor and subsequently hepatitis $\mathrm{E}$ developed. To prove that the infections were definitely donor derived, we phylogenetically compared recipient HEV sequences with the original donor sequence. Persistent HEV infection was defined as detection of HEV RNA in plasma for $>3$ months (20). If archived samples were unavailable, persistent hepatitis for 3 months before the first positive HEV RNA result was also defined as persistent HEV infection.

\section{Results}

\section{The Outbreak}

On posttransplantation day 127, detection of HEV RNA in plasma from a liver transplant recipient at Queen Mary Hospital led to a diagnosis of hepatitis E, at the time attributed to autochthonous foodborne acquisition. On posttransplantation day 162, HEV RNA was detected in plasma from a lung transplant recipient at Queen Mary Hospital. Both patients had undergone transplantation at Queen Mary Hospital on February 28, 2018, and had received organs from the same deceased donor. Archived donor serum was tested by HEV qRT-PCR and found to be positive. Because both kidneys and the heart had also been harvested from this donor, samples were collected from the 3 corresponding recipients, and HEV RNA was detected in the plasma of all 3. Phylogenetic analysis confirmed that HEV partial RNA-dependent RNA polymerase sequences from the donor and 5 organ recipients were identical and belonged to genotype $4 b$ (Figure 1). All 5 recipients fulfilled criteria for persistent HEV infection according to the case definition used in this study. Except for the lung transplant recipient, who died before hepatitis E infection could be confirmed, all patients were counseled about the diagnosis and prescribed ribavirin. When possible, their immunosuppression was reduced. For each patient, plasma and serum samples archived before and after transplantation were retrieved for HEV qRT-PCR and serology testing. The timeline of the outbreak is depicted in Figure 2, and individual case details are summarized in Table 1.

\section{Organ Donor}

The organ donor was a previously healthy 29-year-old woman admitted to Princess Margaret Hospital for acute subarachnoid hemorrhage that led to brainstem death. Alanine aminotransferase (ALT) level was $18 \mathrm{U} / \mathrm{L}$ (reference range 8-58 U/L), aspartate aminotransferase (AST) $22 \mathrm{U} / \mathrm{L}$ (reference range $15-38 \mathrm{U} / \mathrm{L}$ ), and bilirubin $16 \mu \mathrm{mol} / \mathrm{L}$ (reference range 4-23 $\mu \mathrm{mol} / \mathrm{L}$ ). On hospitalization day 4 (February 28 , 2018), her heart, liver, lungs, and kidneys were harvested and transplanted to 5 recipients. After hepatitis $\mathrm{E}$ in the organ recipients was recognized, HEV qRT-PCR was performed on archived donor serum collected on the day of organ harvest; viral load was $2.87 \times 10^{5}$ copies $/ \mathrm{mL}$. This serum sample was negative for HEV IgM and IgG by both ELISAs and the Western blot (Appendix Figure 1). HEV RNA was detected in liver graft tissue; viral load was $2.88 \times 10^{2}$ copies/reaction. Histology of liver graft tissue showed minimal inflammation at portal tracts, and immunohistochemical staining that used HEV monoclonal antibodies did not show positive signals (Appendix Figure 2, panels A, B).

\section{Case-Patient 1 (Liver Graft Recipient)}

The index case-patient was a 66-year-old man with a history of liver cirrhosis caused by hepatitis $\mathrm{C}$ virus infection that had been cured with direct-acting antiviral medications. During his liver transplantation, he received basiliximab and hydrocortisone for intraoperative immunosuppression. Postoperatively, immunosuppression was maintained with tacrolimus, mycophenolate, and prednisolone. After transplantation, his liver function test results initially normalized, but on posttransplantation day 40 , ALT rose to 62 $\mathrm{U} / \mathrm{L}$. Liver function test results abruptly worsened, reaching a nadir on posttransplantation day 123 (bilirubin 85 $\mu \mathrm{mol} / \mathrm{L}$, ALT 1,478 U/L, and AST $561 \mathrm{U} / \mathrm{L}$ ). Prothrombin time was elevated to 14.2 seconds. Liver histology on posttransplantation day 122 showed moderate inflammation at 


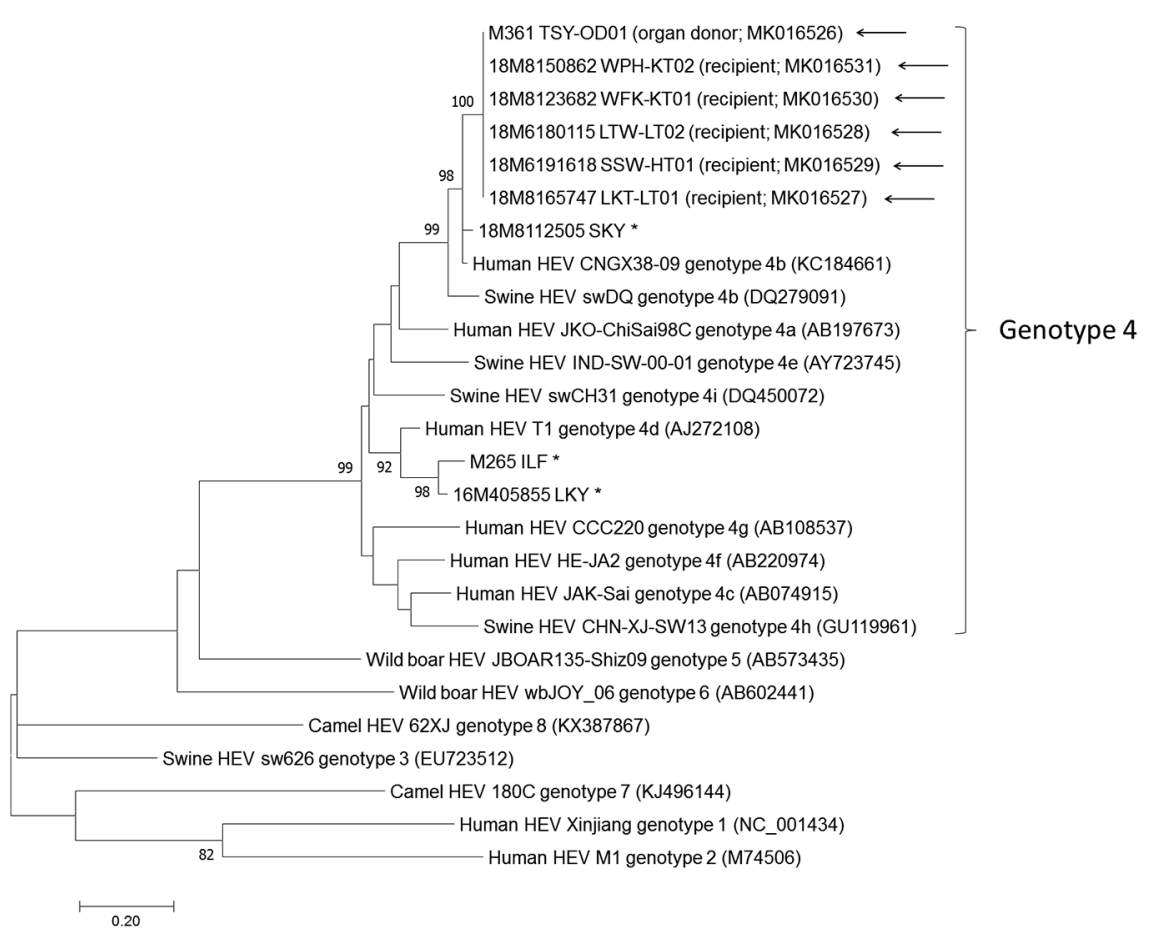

Figure 1. Phylogenetic analyses of the partial RNA-dependent RNA polymerase region of HEV strains involved in study of donor-derived genotype 4 HEV infection, Hong Kong, China, 2018, and other HEV genotypes. The bootstrap analysis was performed with 1,000 replicates. Bootstrap values $<70 \%$ are not shown. The analysis included 382 nt positions. GenBank accession numbers are shown in parentheses. Asterisks $\left({ }^{*}\right)$ indicate locally identified cases of HEV infection; arrows $(\leftarrow)$ indicate HEV outbreak cases from this study. Scale bar indicates estimated number of substitutions per site. HEV, hepatitis E virus. portal tracts (Figure 3, panel A). Acute organ rejection was treated by increasing immunosuppression. Hepatitis $\mathrm{E}$ was diagnosed after HEV RNA was detected in EDTA-treated blood collected on posttransplantation day 127. Immunohistochemical staining of the posttransplantation day 122 liver biopsy sample, with monoclonal antibodies against $\mathrm{HEV}$, showed granular cytoplasmic staining of groups of hepatocytes (Figure 3, panel B). HEV RNA load in this biopsy sample was $1.21 \times 10^{7}$ copies/reaction. Because the patient's liver function test results were spontaneously improving (Figure 4, panel A), immunosuppression was reduced and HEV RNA loads monitored. However, the patient was repeatedly admitted for ascites, and HEV RNA was persistently detected in plasma with mildly elevated ALT. In view of persistent HEV infection and portal hypertension, oral ribavirin $(200 \mathrm{mg} / 400 \mathrm{mg}$ on alternate days, dose adjusted for renal impairment) was started on posttransplantation day 177; viremia cleared within 2 months (Figure 4, panel A).

\section{Case-Patient 2 (Lung Transplant Recipient)}

A 59-year-old man with a history of bronchiectasis and chronic obstructive pulmonary disease underwent sequential bilateral lung transplantation. The procedure was complicated by bleeding requiring exploratory thoracotomy for hemostasis. For postoperative immunosuppression, the patient was administered tacrolimus, mycophenolate, and prednisolone. The patient required prolonged hospitalization for ventilator-associated pneumonia. Starting at posttransplantation day 65 , he had low-grade hepatitis. ALT was elevated to $65 \mathrm{U} / \mathrm{L}, \mathrm{AST}$ to $45 \mathrm{U} / \mathrm{L}$, while bilirubin remained within normal limits. Over the next 3 months, ALT elevations persisted (Figure 4, panel B). On posttransplantation day 161 , the patient experienced generalized tonic-clonic convulsion and vesicular rash over the groin. Disseminated herpes zoster was confirmed by detection of varicella zoster virus DNA in cerebrospinal fluid, plasma, and swab samples from the vesicular rash. Despite intravenous acyclovir, the patient's condition progressively deteriorated to refractory shock, coagulopathy, and then death on posttransplantation day 171. Postmortem qRT-PCR testing of a plasma sample sent on posttransplantation day 162 confirmed a diagnosis of hepatitis E. An archived sample from posttransplantation day 21 that had been positive for HEV RNA confirmed persistent HEV infection (Figure 4, panel B). IgG in baseline pretransplant serum was detectable by ELISA, but this finding could not be confirmed by Western blot (Appendix Figure 1).

\section{Case-Patient 3 (Kidney Transplant Recipient)}

A 6-year-old boy with focal segmental glomerulosclerosis underwent kidney transplantation at Princess Margaret Hospital. Immunosuppression was induced with methylprednisolone and basiliximab and maintained with oral tacrolimus, mycophenolate, and prednisolone. Mycophenolate was switched to azathioprine because of BK virus reactivation. Starting at posttransplantation day 67, persistent ALT level abnormalities were noted. Because hepatitis E had been 
diagnosed in 2 other recipients of organs from the same donor, HEV qRT-PCR testing of plasma collected on posttransplantation day 177 was performed, and results confirmed the diagnosis of persistent HEV infection. Administration of tacrolimus and azathioprine was stopped, and immunosuppression was continued with cyclosporin A, everolimus, and prednisolone. On posttransplantation day 180 , oral ribavirin (100 mg $2 \times / \mathrm{d})$ was started. Liver function test results improved; HEV viral load underwent a 1-log reduction after the patient had received ribavirin for 1 month (Figure 4, panel C). However, during the second month of treatment, viral load and liver function test results plateaued.

\section{Case-Patient 4 (Kidney Transplant Recipient)}

A 54-year-old woman with chronic glomerulonephritis underwent kidney transplantation at Princess Margaret Hospital. Preoperatively, she received antithymocyte globulin and methylprednisolone. Postoperative immunosuppression included tacrolimus, mycophenolate, and prednisolone.
During follow-up at Tuen Mun Hospital on posttransplantation day 54, abnormal parenchymal enzymes were first noted, coinciding with an increasing trend in tacrolimus levels detected in May (Figure 4, panel D); in addition, ALT was elevated to $59 \mathrm{U} / \mathrm{L}$, ALP was $442 \mathrm{U} / \mathrm{L}$, and bilirubin levels were within reference range at $8 \mu \mathrm{mol} / \mathrm{L}$. The result of HEV qRT-PCR of plasma collected on posttransplantation day 176 was positive. Tacrolimus dosage was reduced, and oral ribavirin (400 mg $1 \times /$ day) was started. Within 2 months of treatment, ALT levels normalized and viremia cleared (Figure 4, panel D).

\section{Case-Patient 5 (Heart Transplant Recipient)}

A 49-year-old woman received a heart transplant for severe myocarditis at Queen Mary Hospital. Intraoperatively, she received $500 \mathrm{mg}$ intravenous methylprednisolone; postoperatively, as an outpatient, she received immunosuppression with tacrolimus, mycophenolate, and prednisolone. On posttransplantation day 34, abnormal liver function

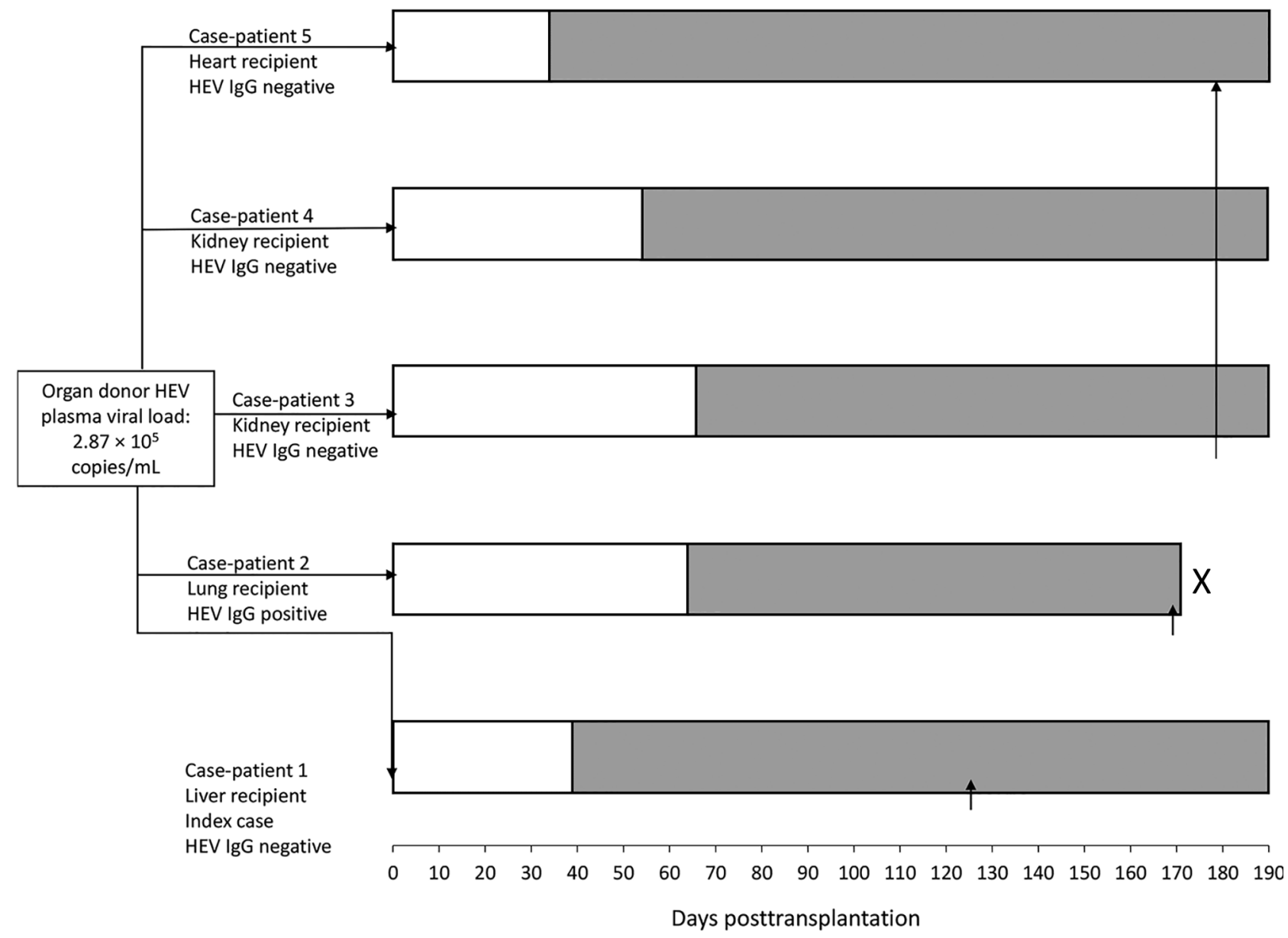

Figure 2. Timeline of outbreak in study of donor-derived genotype 4 HEV infection, Hong Kong, China, 2018, showing baseline HEV IgG status of each organ recipient. White bars indicate incubation period during which liver function test results were within reference range. Gray bars indicate timeline of alanine aminotransferase derangement after transplantation. X indicates patient death. Vertical arrows ( $\uparrow$ ) indicate time of hepatitis $E$ diagnosis. HEV, hepatitis $E$ virus. 
Table 1. Characteristics of 5 patients who received organs from the same donor and had donor-derived genotype 4 hepatitis $E$ virus infection, Hong Kong, China, 2018*

\begin{tabular}{|c|c|c|c|c|c|}
\hline Case-patient & 1 & 2 & 3 & 4 & 5 \\
\hline Organ transplanted & Liver & Lung & Kidney & Kidney & Heart \\
\hline Age, $y / \operatorname{sex}$ & $66 / \mathrm{M}$ & $59 / \mathrm{M}$ & $6 / \mathrm{M}$ & $54 / F$ & $48 / \mathrm{F}$ \\
\hline Incubation period, $\mathrm{d} \dagger$ & 40 & 65 & 67 & 54 & 34 \\
\hline Signs/symptoms & Ascites & None & None & None & None \\
\hline Peak ALT level, U/L & 1,385 & 138 & 490 & 186 & 130 \\
\hline Lymphocytes at hepatitis onset, $\times 10^{9}$ cells $/ \mathrm{L}$ & 0.43 & 0.59 & 1.4 & 0.37 & 1.12 \\
\hline Pretransplantation HEV IgG $\ddagger$ & - & + & - & - & - \\
\hline Pretransplantation HEV-lgG§ & - & - & - & - & - \\
\hline Posttransplantation HEV-lgM/HEV-IgGT & $+/+$ & $+/+$ & $-1-$ & $+1-$ & $-1-$ \\
\hline Posttransplantation HEV-lgM/HEV-IgG $\S$ & $+/+$ & $+/+$ & $-1-$ & $+/+$ & $-1-$ \\
\hline
\end{tabular}

*All patients had received tacrolimus, mycophenolate, and prednisolone before onset of hepatitis $\mathrm{E}$. ALT, alanine aminotransferase; HEV, hepatitis $\mathrm{E}$ virus.

†Time between transplantation and onset of abnormal ALT level.

fHEV lgG ELISA (http://www.ystwt.cn/HEV.html).

§Western blot.

THEV IgM/HEV IgG ELISA (http://www.ystwt.cn/HEV.html).

test results were first noted; ALT was $123 \mathrm{U} / \mathrm{L}$, AST 94 $\mathrm{U} / \mathrm{L}$, and ALP $123 \mathrm{U} / \mathrm{L}$, but bilirubin levels were within reference range. Subsequent blood testing showed ongoing low-grade hepatitis (Figure 4, panel E). Because other transplant-transmitted hepatitis $\mathrm{E}$ infections from the same donor had been recognized, HEV qRT-PCR was performed on posttransplantation day 177; plasma contained an HEV RNA load of $1.51 \times 10^{8}$ copies $/ \mathrm{mL}$. Because the hepatitis had persisted for $>3$ months, on posttransplantation day 181, oral ribavirin ( $200 \mathrm{mg} / \mathrm{d}$, adjusted for renal function) was started, and all immunosuppressant dosages were reduced. At the end of the second month of ribavirin treatment, ALT and HEV RNA loads were improving.

\section{Discussion}

This hepatitis E outbreak affected 5 transplant recipients who had received organs from a donor with HEV viremia. Two previous studies have described HEV transmission from organ donors to recipients $(15,16)$. In both of those studies, liver function test results were abnormal for donors at the time of organ donation; 1 donor had subclinical hepatic HEV carriage (without serum HEV IgM or RNA positivity), and the other had acute hepatitis $\mathrm{E}$ (with serum
HEV IgM and RNA positivity) $(15,16)$. The donor in our study was a young woman whose liver function test results were within reference ranges and whose premortem serum was negative for HEV IgM but positive for HEV RNA; these values are compatible with organ donation during the window period of hepatitis $\mathrm{E}$ infection. However, subclinical long-term HEV carriage without seroconversion, a recently described entity in immunocompetent blood donors $(21,22)$, cannot be excluded. Adoptive transfer of functional hepatitis B immunity via transplantation has been reported $(23,24)$. The lack of measurable HEV humoral antibodies in the donor's serum may have facilitated HEV transmission in the absence of adoptive transfer of anti-HEV immune responses.

The risk for HEV transmission during transplantation has been recognized in the United Kingdom and Spain $(25,26)$; guidelines from both countries recommend organ donor HEV screening. This recommendation is further supported by a recent study that reported that $1(0.95 \%)$ of every 105 liver grafts is contaminated with HEV (27). The screening method of choice is nucleic acid amplification testing (NAAT), which is more sensitive than serologic testing $(13,28)$. Undetectable HEV RNA in donor
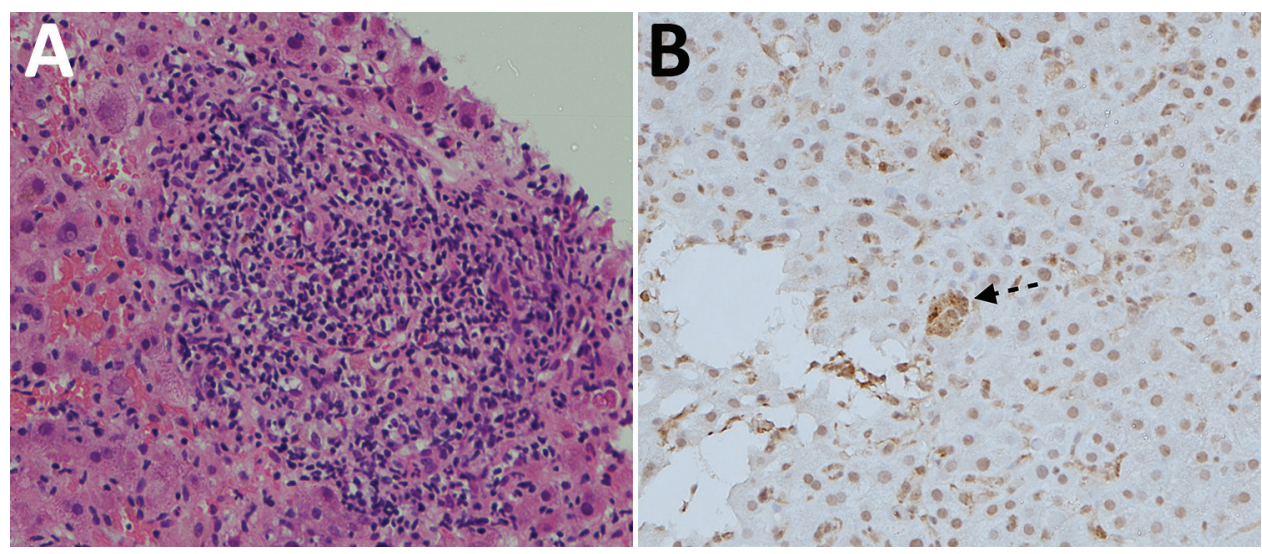

Figure 3. Histology of tissue from liver graft of hepatitis $E$ virus case-patient 1, a 66-yearold man, on posttransplantation day 122. A) Hematoxylin and eosin staining showing moderate (grade 2) inflammation. B) Immunohistochemical staining (using hepatitis $\mathrm{E}$ virus monoclonal antibody); arrow indicates small groups of hepatocytes with positive cytoplasmic signals. Original magnification $\times 200$. 
A

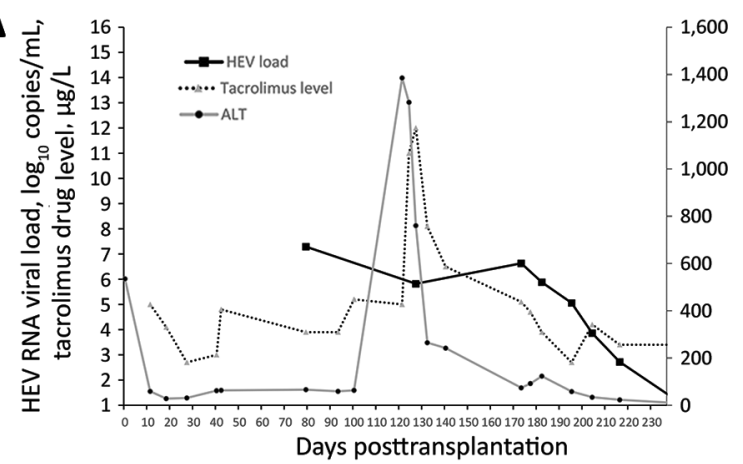

C

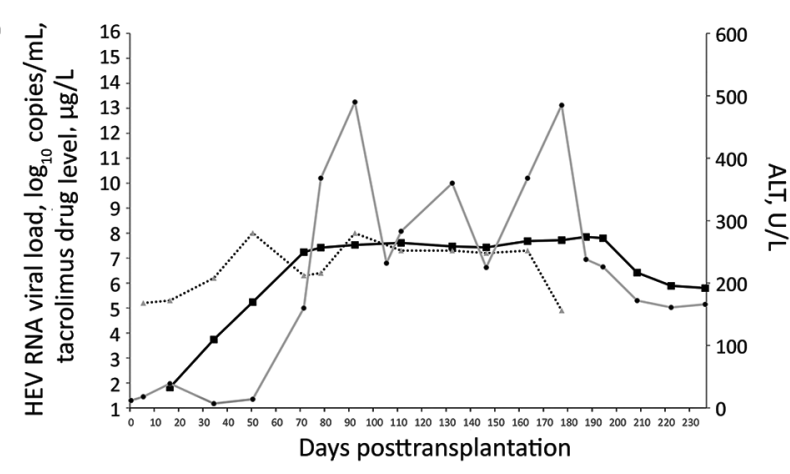

E

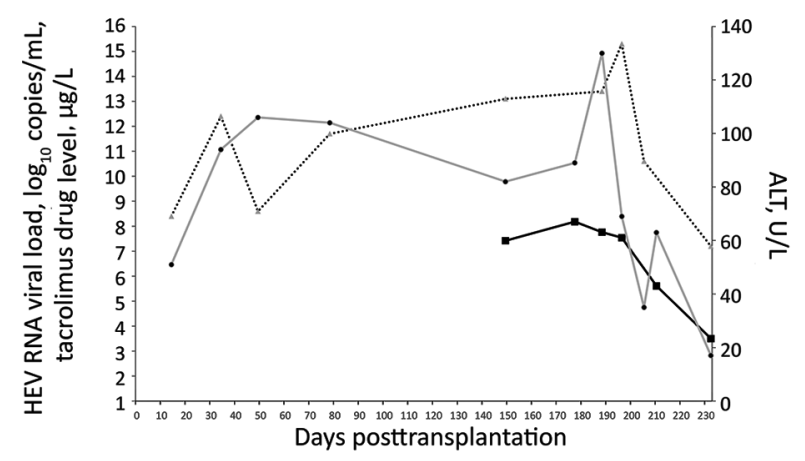

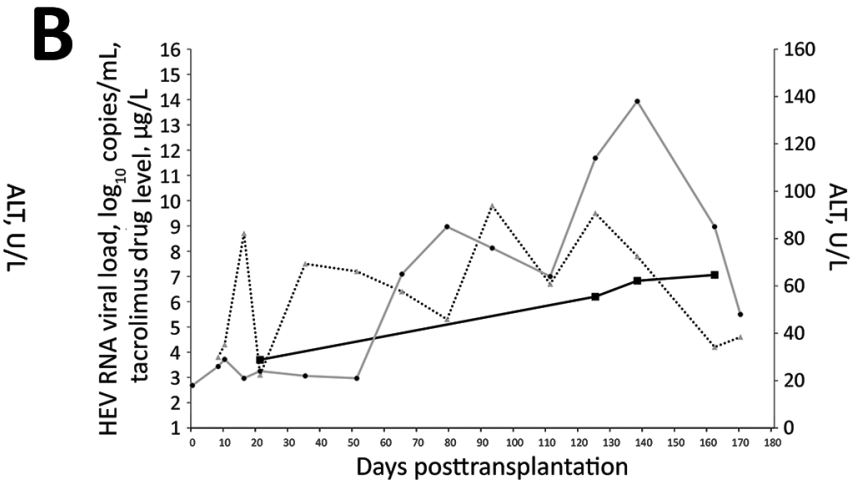

D

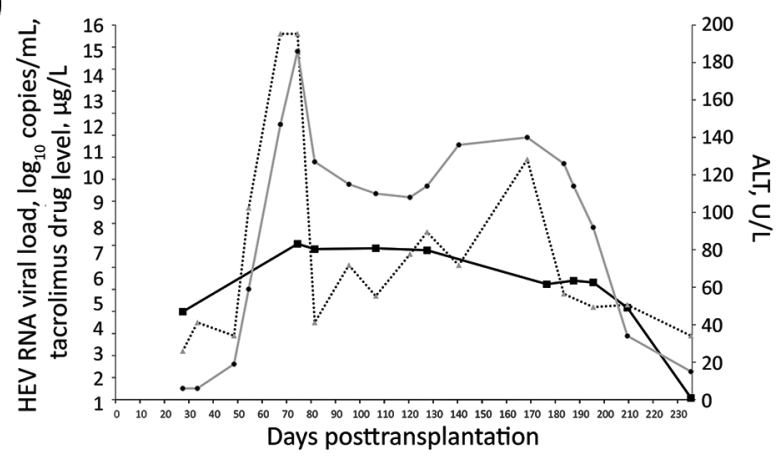

Figure 4. Kinetics of liver function test (ALT) results, tacrolimus levels, and plasma HEV RNA load with relation to ribavirin therapy. A) Case-patient 1; B) case-patient 2; C) case-patient 3; D) case-patient 4; E) case-patient 5. Date for case-patients $1,3,4$, and 5 were updated up to week 8 of ribavirin treatment. Horizontal black bars indicate when patient began taking oral ribavirin. ALT, alanine aminotransferase; HEV, hepatitis E virus. serum would indicate low risk for HEV transmission, but the experience of Schlosser et al. suggests that liver grafts may harbor infectious HEV RNA even in the absence of systemic markers of infection (15). The most sensitive screening method may be HEV NAAT of graft tissue samples obtained at the time of transplantation. Although NAAT results may not be available before transplantation, the detection of HEV RNA in graft tissues could be used to guide posttransplant management of recipients. However, in resource-limited settings, the decision to implement universal organ donor HEV screening would pose substantial difficulties. Furthermore, even if the organ donor is HEV negative, recipients remain vulnerable to HEV infection through dietary and blood product transfusion routes. Ultimately, the decision to screen organ donors will depend on trends in HEV incidence in the general population. Screening organ donors in areas of low HEV prevalence may not add much value to transplant safety.

In our study, for all 5 organ recipients, hepatitis developed within a mean of 52 days after transplantation. The kidney, heart, and lung recipients showed no symptoms of hepatitis, but the liver recipient had severe hepatitis. This discrepancy is probably the consequence of an inflammatory response to high HEV antigenic load in the liver graft. Although the hepatitis in the liver graft recipient was temporarily suppressed by an increased dosage of immunosuppressants, graft dysfunction progressed to portal hypertension and refractory ascites, eventually requiring treatment with ribavirin.

$\mathrm{HEV}$ IgG is considered to provide cross-genotypic protection against HEV infection $(29,30)$. In this outbreak, both ELISA and the Western blot results indicated that 4 of 
Table 2. Summary of studies describing HEV-4 infections in immunocompromised patients*

\begin{tabular}{|c|c|c|c|c|c|c|}
\hline Reference & $\begin{array}{l}\text { Patient } \\
\text { age, y/sex }\end{array}$ & $\begin{array}{c}\text { Underlying } \\
\text { immunosuppressive } \\
\text { condition/treatment }\end{array}$ & $\begin{array}{c}\text { Peak } \\
\text { ALT, U/L }\end{array}$ & $\begin{array}{l}\text { Progression to } \\
\text { persistent HEV } \\
\text { infection }\end{array}$ & $\begin{array}{l}\text { Ribavirin } \\
\text { treatment/ } \\
\text { response }\end{array}$ & Patient outcome \\
\hline$(37)$ & $4 / \mathrm{M}$ & Acute lymphoblastic leukemia & 585 & $\begin{array}{c}\text { Spontaneous } \\
\text { clearance, relapsed } \\
20 \text { mo later }\end{array}$ & No & $\begin{array}{l}\text { Spontaneous clearance of } \\
\text { relapse; resolution of } \\
\text { hepatitis }\end{array}$ \\
\hline (36) & $68 / \mathrm{M}$ & Liver transplantation/tacrolimus & 149 & Yes & Yes/yes & $\begin{array}{l}\text { Required retransplantation } \\
\text { because of accelerated liver } \\
\text { fibrosis; patient died of } \\
\text { hemorrhage }\end{array}$ \\
\hline (35) & $47 / F$ & Liver transplantation/tacrolimus & $\begin{array}{c}\text { Not } \\
\text { reported }\end{array}$ & Yes & Yes/no & $\begin{array}{l}\text { Progressive cholestasis; } \\
\text { patient died of sepsis }\end{array}$ \\
\hline (11) & $52 / \mathrm{M}$ & $\begin{array}{c}\text { Renal } \\
\text { transplantation/prednisolone, }\end{array}$ & 230 & Yes & Yes/no & $\begin{array}{l}\text { Ribavirin resistance; } \\
\text { progressive cirrhosis }\end{array}$ \\
\hline & $55 / \mathrm{M}$ & cyclosporin $A$, and everolimus & 456 & Yes & Yes/yes & Resolution of hepatitis \\
\hline & $65 / \mathrm{M}$ & or sirolimus & 470 & Yes & Yes/yes & Resolution of hepatitis \\
\hline (38) & $36 / \mathrm{M}$ & $\begin{array}{l}\text { Renal transplantation/ } \\
\text { tacrolimus }\end{array}$ & 300 & Yes & Yes/yes & $\begin{array}{l}\text { Relapse after ribavirin } \\
\text { withheld; progressive } \\
\text { hepatitis }\end{array}$ \\
\hline
\end{tabular}

5 patients were HEV IgG negative before transplantation, indicating absence of protective immunity from previous exposure. This finding is consistent with our previous findings of high HEV susceptibility among transplant recipients in Hong Kong (31).

The HEV strain in the outbreak reported here belonged to genotype 4b. Although some studies found that HEV4 acute infection is more severe than HEV-3 infection $(32,33)$, this finding has not been corroborated by a recent systematic review (34). Few data on the clinical characteristics of HEV-4 infection in immunocompromised patients are available $(11,35-38)$. Of the 7 reported cases of HEV-4 infection in immunocompromised patients, 6 cases progressed to persistent infection; in 3 cases, infection did not respond to ribavirin or relapsed despite ribavirin (Table 2). All 5 patients in our study experienced persistent HEV4 infection. Combined with the findings of our previous study (11), we note that persistent HEV-4 infection developed in $8(89 \%)$ of 9 transplant recipients with hepatitis E in Hong Kong. In 4 patients from this study (case-patients 1-4) and 2 from our previous study (11), immunosuppression was reduced without any effect on HEV-4 viral load. This experience contrasts with findings of a previous seminal study in which HEV-3 infection cleared spontaneously even without reduction of immunosuppression in $34 \%$ of HEV-3 infected transplant recipients and cleared after reduction of immunosuppression in another $21 \%(39)$. The patients in our study were either taking tacrolimus or mTOR (mammalian target of rapamycin) inhibitors, which are risk factors for viral persistence $(39,40)$. However, the effect of HEV genotype on persistence of infection requires further exploration.

All 4 surviving patients received ribavirin, which has been shown to be effective for treating persistent HEV-3 infections $(41)$. At the time this article was written $(\approx 2$ months after patients started taking ribavirin), ALT levels had improved for all 4 patients, and viremia had cleared for 2 patients. Reduction of HEV viral load was slower for case-patient 3 and plateaued at the end of the second month of treatment. Further follow-up of this patient is needed to confirm whether this is ribavirin refractory disease, which we have previously described for HEV-4 infections (11).

Our study has several limitations. We were unable to ascertain the exact route of infection in the donor because of the long duration ( $\approx 6$ months) between organ donation and recognition of the outbreak. Because archived blood samples obtained from recipients shortly after transplantation were not available, we were unable to comprehensively examine the viral load dynamics of HEV infection. The variable performance of HEV serologic assays and lack of a standard serologic test is a limitation of our study, which we tried to minimize by using 2 independent assay formats. Although some research findings suggest that the analytical sensitivity and specificity of the Wantai HEV IgG and IgM ELISAs are good, the work of Cattoir et al. shows that discordant results with other commercial assays are not uncommon $(42,43)$. In our study, we found $100 \%$ concordance in HEV IgM detection between both formats, but the Western blot was able to detect HEV IgG in 1 more casepatient than the Wantai ELISA. Furthermore, the Wantai ELISA result indicated that case-patient 2 had HEV IgG in pretransplant serum, but this finding was not confirmed by Western blot.

We recognize that definitive conclusions on HEV-4 infections cannot be based on limited case series. To delineate intergenotypic differences in clinical characteristics, natural history, and ribavirin responsiveness, prospective studies of HEV-4 infection in cohorts of immunocompromised patients are needed. 
This study was supported by donations from Shaw Foundation, Hong Kong, and by Michael Seak-Kan Tong. The study was partially funded by the Consultancy Service for Enhancing Laboratory Surveillance of Emerging Infectious Disease for Department of Health of the Hong Kong Special Administrative Region of China, Seed Fund for Basic Research, and Enhanced New Staff Start-up Research Grant of the University of Hong Kong.

S.S. has received speaker's honoraria from Sanofi-Pasteur Corporation. J.F.W.C. received travel grants from Pfizer Corporation Hong Kong and Astellas Pharma Hong Kong Corporation Limited and was an invited speaker for Gilead Sciences Hong Kong Limited and Luminex Corporation.

\section{About the Author}

Dr. Sridhar is a clinical assistant professor at the Department of Microbiology, The University of Hong Kong, Hong Kong. His major research interests include viral hepatitis, hepatitis E, and clinical virology.

\section{References}

1. Rein DB, Stevens GA, Theaker J, Wittenborn JS, Wiersma ST. The global burden of hepatitis E virus genotypes 1 and 2 in 2005. Hepatology. 2012;55:988-97. http://dx.doi.org/10.1002/ hep. 25505

2. Kamar N, Selves J, Mansuy JM, Ouezzani L, Péron JM, Guitard J, et al. Hepatitis E virus and chronic hepatitis in organ-transplant recipients. N Engl J Med. 2008;358:811-7. http://dx.doi. org/10.1056/NEJMoa0706992

3. Sridhar S, Teng JLL, Chiu TH, Lau SKP, Woo PCY. Hepatitis E virus genotypes and evolution: emergence of camel hepatitis $\mathrm{E}$ variants. Int J Mol Sci. 2017;18:E869. http://dx.doi.org/10.3390/ ijms 18040869

4. Lapa D, Capobianchi MR, Garbuglia AR. Epidemiology of hepatitis E virus in European countries. Int J Mol Sci. 2015;16:25711-43. http://dx.doi.org/10.3390/ijms161025711

5. Pisano MB, Martinez-Wassaf MG, Mirazo S, Fantilli A, Arbiza J, Debes JD, et al. Hepatitis E virus in South America: the current scenario. Liver Int. 2018;38:1536-46. http://dx.doi.org/10.1111/ liv. 13881

6. Cossaboom CM, Heffron CL, Cao D, Yugo DM, Houk-Miles AE, Lindsay DS, et al. Risk factors and sources of foodborne hepatitis E virus infection in the United States. J Med Virol. 2016;88:1641-5. http://dx.doi.org/10.1002/jmv.24497

7. Sarkar S, Rivera EM, Engle RE, Nguyen HT, Schechterly CA, Alter HJ, et al. An epidemiologic investigation of a case of acute hepatitis E. J Clin Microbiol. 2015;53:3547-52. http://dx.doi.org/ 10.1128/JCM.01189-15

8. Te HS, Drobeniuc J, Kamili S, Dong C, Hart J, Sharapov UM. Hepatitis $\mathrm{E}$ virus infection in a liver transplant recipient in the United States: a case report. Transplant Proc. 2013;45:810-3. http://dx.doi.org/10.1016/j.transproceed.2012.08.020

9. Geng Y, Zhao C, Fan J, Harrison TJ, Zhang H, Lian H, et al. Genotype analysis of hepatitis E virus from sporadic hepatitis E cases in northern China. Infect Genet Evol. 2013;20:413-7. http://dx.doi.org/10.1016/j.meegid.2013.10.003

10. Sridhar S, Lo SK, Xing F, Yang J, Ye H, Chan JF, et al. Clinical characteristics and molecular epidemiology of hepatitis E in Shenzhen, China: a shift toward foodborne transmission of hepatitis E virus infection. Emerg Microbes Infect. 2017;6:e115. http://dx.doi.org/10.1038/emi.2017.107

11. Sridhar S, Chan JFW, Yap DYH, Teng JLL, Huang C, Yip CCY, et al. Genotype 4 hepatitis E virus is a cause of chronic hepatitis in renal transplant recipients in Hong Kong. J Viral Hepat. 2017.

12. Colson P, Coze C, Gallian P, Henry M, De Micco P, Tamalet C. Transfusion-associated hepatitis E, France. Emerg Infect Dis. 2007;13:648-9. http://dx.doi.org/10.3201/eid1304.061387

13. Hewitt PE, Ijaz S, Brailsford SR, Brett R, Dicks S, Haywood B, et al. Hepatitis $\mathrm{E}$ virus in blood components: a prevalence and transmission study in southeast England. Lancet. 2014;384: 1766-73. http://dx.doi.org/10.1016/S0140-6736(14)61034-5

14. Domanović D, Tedder R, Blümel J, Zaaijer H, Gallian P, Niederhauser C, et al. Hepatitis E and blood donation safety in selected European countries: a shift to screening? Euro Surveill. 2017;22:30514. http://dx.doi.org/10.2807/1560-7917. ES.2017.22.16.30514

15. Schlosser B, Stein A, Neuhaus R, Pahl S, Ramez B, Krüger DH, et al. Liver transplant from a donor with occult HEV infection induced chronic hepatitis and cirrhosis in the recipient. J Hepatol. 2012;56:500-2. http://dx.doi.org/10.1016/j.jhep.2011.06.021

16. Pourbaix A, Ouali N, Soussan P, Roque Afonso AM, Péraldi MN, Rondeau E, et al. Evidence of hepatitis E virus transmission by renal graft. Transpl Infect Dis. 2017;19:e12624. http://dx.doi.org/ 10.1111/tid.12624

17. Sridhar S, Yip CCY, Wu S, Cai J, Zhang AJ, Leung KH, et al. Rat hepatitis E virus as cause of persistent hepatitis after liver transplant. Emerg Infect Dis. 2018;24:2241-50. http://dx.doi.org/ 10.3201/eid2412.180937

18. Jothikumar N, Cromeans TL, Robertson BH, Meng XJ, Hill VR. A broadly reactive one-step real-time RT-PCR assay for rapid and sensitive detection of hepatitis E virus. J Virol Methods. 2006;131:65-71. http://dx.doi.org/10.1016/j.jviromet.2005.07.004

19. Chan JF, Zhang AJ, Chan CC, Yip CC, Mak WW, Zhu H, et al. Zika virus infection in dexamethasone-immunosuppressed mice demonstrating disseminated infection with multi-organ involvement including orchitis effectively treated by recombinant type I interferons. EBioMedicine. 2016;14:112-22. http://dx.doi.org/ 10.1016/j.ebiom.2016.11.017

20. Kamar N, Rostaing L, Legrand-Abravanel F, Izopet J. How should hepatitis $\mathrm{E}$ virus infection be defined in organ-transplant recipients? Am J Transplant. 2013;13:1935-6. http://dx.doi.org/ 10.1111/ajt.12253

21. Wen GP, Chen CR, Song XY, Tang ZM, Ji WF, Wang SL, et al. Long-term HEV carriers without antibody seroconversion among eligible immunocompetent blood donors. Emerg Microbes Infect. 2018;7:125. http://dx.doi.org/10.1038/s41426-018-0125-y

22. Kraef C, Schlein C, Hiller J, Westhölter D, Denzer U, Horvatits T, et al. Course of HEV viremia and anti-HEV IgM/IgG response in asymptomatic blood donors. J Clin Virol. 2018;105:26-30. http://dx.doi.org/10.1016/j.jcv.2018.05.013

23. Schumann A, Lindemann M, Valentin-Gamazo C, Lu M, Elmaagacli A, Dahmen U, et al. Adoptive immune transfer of hepatitis B virus specific immunity from immunized living liver donors to liver recipients. Transplantation. 2009;87:103-11. http://dx.doi.org/10.1097/TP.0b013e31818bfc85

24. Lo CM, Fung JT, Lau GK, Liu CL, Cheung ST, Lai CL, et al. Development of antibody to hepatitis B surface antigen after liver transplantation for chronic hepatitis B. Hepatology. 2003;37:36-43. http://dx.doi.org/10.1053/jhep.2003.50035

25. British Transplantation Guidelines. Guidelines for hepatitis E and solid organ transplantation 2017 [cited 2018 Sep 8]. https://bts.org.uk/wp-content/uploads/2017/05/BTS-HEVGuideline-CONSULTATION_DRAFT.pdf

26. Study Group for Viral Hepatitis. Consensus document of the diagnosis, management, and prevention of infection with the 
hepatitis E virus [cited 2018 Sep 22]. https://www.seimc.org/ contenidos/gruposdeestudio/gehep/dcientificos/documentos/ gehep-seimc-dc-2018-HepatitisE_Version_En.pdf

27. Rivero-Juarez A, Aguado R, Lopez-Lopez P, Sanchez-Frias M, Frias M, Briceño J, et al. Prevalence of hepatitis E virus infection in liver donors in Spain. Clin Microbiol Infect. 2018;24:1218-9. http://dx.doi.org/10.1016/j.cmi.2018.06.030

28. Tedder RS, Tettmar KI, Brailsford SR, Said B, Ushiro-Lumb I, Kitchen A, et al. Virology, serology, and demography of hepatitis E viremic blood donors in South East England. Transfusion. 2016;56:1529-36. http://dx.doi.org/10.1111/trf.13498

29. Bryan JP, Tsarev SA, Iqbal M, Ticehurst J, Emerson S, Ahmed A, et al. Epidemic hepatitis E in Pakistan: patterns of serologic response and evidence that antibody to hepatitis $\mathrm{E}$ virus protects against disease. J Infect Dis. 1994;170:517-21. http://dx.doi.org/ 10.1093/infdis/170.3.517

30. Huang W, Zhang H, Harrison TJ, Lang S, Huang G, Wang Y. Cross-protection of hepatitis $\mathrm{E}$ virus genotypes 1 and 4 in rhesus macaques. J Med Virol. 2008;80:824-32. http://dx.doi.org/10.1002/ jmv. 21140

31. Sridhar S. Serological susceptibility of immunocompromised transplant recipients to hepatitis E infection in Hong Kong: a hepatitis E virus genotype 4 endemic region. Presented at: 17th Asia-Pacific Congress of Clinical Microbiology and Infection; 2018 Aug 30-Sep 2; Hong Kong.

32. Mizuo H, Yazaki Y, Sugawara K, Tsuda F, Takahashi M, Nishizawa T, et al. Possible risk factors for the transmission of hepatitis $\mathrm{E}$ virus and for the severe form of hepatitis $\mathrm{E}$ acquired locally in Hokkaido, Japan. J Med Virol. 2005;76:341-9. http://dx.doi.org/10.1002/jmv.20364

33. Jeblaoui A, Haim-Boukobza S, Marchadier E, Mokhtari C, Roque-Afonso AM. Genotype 4 hepatitis E virus in France: an autochthonous infection with a more severe presentation. Clin Infect Dis. 2013;57:e122-6. http://dx.doi.org/10.1093/cid/cit291

34 Haffar S, Shalimar, Kaur RJ, Wang Z, Prokop LJ, Murad MH, et al. Acute liver failure caused by hepatitis $\mathrm{E}$ virus genotype 3 and 4: a systematic review and pooled analysis. Liver Int. 2018;38:1965-73.

35. Wu CH, Ho CM, Tsai JH, Sun HY, Hu RH, Lee PH. First case genotype 4 hepatitis E infection after a liver transplant. Exp Clin Transplant. 2015;15:228-30.
36. Perumpail RB, Ahmed A, Higgins JP, So SK, Cochran JL, Drobeniuc J, et al. Fatal accelerated cirrhosis after imported HEV genotype 4 infection. Emerg Infect Dis. 2015;21:1679-81. http://dx.doi.org/10.3201/eid2109.150300

37. Geng Y, Zhang H, Huang W, J Harrison T, Geng K, Li Z, et al. Persistent hepatitis E virus genotype 4 infection in a child with acute lymphoblastic leukemia. Hepat Mon. 2014;14:e15618.

38. Wang Y, Chen G, Pan Q, Zhao J. Chronic hepatitis E in a renal transplant recipient: the first report of genotype 4 hepatitis $\mathrm{E}$ virus caused chronic infection in organ recipient. Gastroenterology. 2018;154:1199-201. http://dx.doi.org/10.1053/j.gastro.2017.12.028

39. Kamar N, Garrouste C, Haagsma EB, Garrigue V, Pischke S, Chauvet $\mathrm{C}$, et al. Factors associated with chronic hepatitis in patients with hepatitis $\mathrm{E}$ virus infection who have received solid organ transplants. Gastroenterology. 2011;140:1481-9. http://dx.doi.org/10.1053/j.gastro.2011.02.050

40. Zhou X, Wang Y, Metselaar HJ, Janssen HL, Peppelenbosch MP, Pan Q. Rapamycin and everolimus facilitate hepatitis E virus replication: revealing a basal defense mechanism of PI3KPKB-mTOR pathway. J Hepatol. 2014;61:746-54. http://dx.doi.org/10.1016/j.jhep.2014.05.026

41. Kamar N, Izopet J, Tripon S, Bismuth M, Hillaire S, Dumortier J, et al. Ribavirin for chronic hepatitis $\mathrm{E}$ virus infection in transplant recipients. N Engl J Med. 2014;370:1111-20. http://dx.doi.org/10.1056/NEJMoa1215246

42. Pas SD, Streefkerk RH, Pronk M, de Man RA, Beersma MF, Osterhaus AD, et al. Diagnostic performance of selected commercial HEV IgM and IgG ELISAs for immunocompromised and immunocompetent patients. J Clin Virol. 2013;58:629-34. http://dx.doi.org/10.1016/j.jcv.2013.10.010

43. Cattoir L, Van Hoecke F, Van Maerken T, Nys E, Ryckaert I, De Boulle M, et al. Hepatitis E virus serology and PCR: does the methodology matter? Arch Virol. 2017;162:2625-32. http://dx.doi.org/10.1007/s00705-017-3395-0

Address for correspondence: Kwok-Yung Yuen, Carol Yu Centre for Infection, State Key Laboratory of Emerging Infectious Diseases, Department of Microbiology, Li Ka Shing Faculty of Medicine, The University of Hong Kong, Queen Mary Hospital, Pokfulam, Hong Kong, China; email: kyyuen@hkucc.hku.hk 